\title{
Insulin gene promoter methylation status in Greek children and adolescents with Type 1 Diabetes
}

\author{
KONSTANTINA MOUZAKI ${ }^{1,2}$, ELENI P. KOTANIDOU ${ }^{1}$, AIKATERINI FRAGOU ${ }^{2}$, IOANNIS KYRGIOS ${ }^{1}$, \\ STYLIANI GIZA ${ }^{1}$, ANGELIKI KLEISARCHAKI ${ }^{1}$, VASILIKI RENGINA TSINOPOULOU ${ }^{1}$, \\ ANASTASIOS SERBIS $^{1}$, GEORGIOS TZIMAGIORGIS ${ }^{2}$ and ASSIMINA GALLI-TSINOPOULOU ${ }^{1}$ \\ ${ }^{1}$ Second Department of Paediatrics, School of Medicine, Faculty of Health Sciences, Aristotle University of Thessaloniki, \\ AHEPA General Hospital, 54636 Thessaloniki; ${ }^{2}$ Laboratory of Biological Chemistry, School of Medicine, \\ Faculty of Health Sciences, Aristotle University of Thessaloniki, 54124 Thessaloniki, Greece
}

Received March 4, 2020; Accepted June 24, 2020

DOI: $10.3892 /$ br.2020.1338

\begin{abstract}
The insulin (INS) gene is the one of the most important genes involved in the pathogenesis of Type 1 Diabetes (T1D) after the Major Histocompatibility Complex genes. Studies addressing the issue of hyper- or hypo-methylation status of the INS gene promoter have reported inconsistent results. The majority of studies showed hypomethylation; however a few studies have shown hypermethylation at specific cytosine-guanosine $(\mathrm{CpG})$ sites in the promoter region of the INS gene. The aim of the present study was to analyze the methylation status of the promoter region of the INS gene in Greek children and adolescents with T1D. A total of 20 T1D participants (mean diabetes duration of $6.15 \pm 4.12$ years) and 20 age- and sex-matched controls were enrolled in the present study. DNA was isolated from whole blood samples, modified using sodium bisulfite and analyzed using PCR and electrophoresis. DNA was then pooled with highly reactive supermagnetic beads at similar molar quantities, submitted for library construction and finally sequenced using next-generation sequencing. The methylation profile at $10 \mathrm{CpG}$ sites around the transcription start site (TSS) of the INS promoter was analysed and expressed as the mean \pm standard deviation. The overall mean methylation in patients with T1D did not differ compared with the healthy controls. There was a statistically significant difference between the two groups in hypermethylation at position $-345(\mathrm{P}=0.02)$, while a trend $(\mathrm{P}=0.06)$ at position -102 was observed. According to the results of the present study, increased methylation in the INS
\end{abstract}

Correspondence to: Professor Assimina Galli-Tsinopoulou, Second Department of Paediatrics, School of Medicine, Faculty of Health Sciences, Aristotle University of Thessaloniki, AHEPA General Hospital, Stilponos Kyriakidi 1, 54636 Thessaloniki, Greece

E-mail: agalli@auth.gr

Key words: DNA methylation, Type 1 Diabetes, insulin gene, next-generation sequencing gene promoter at specific $\mathrm{CpG}$ sites around the TSS were already present in childhood T1D. These data may possibly serve as a guide towards the identification of a methylation pattern for detection of development of T1D in genetically predisposed children.

\section{Introduction}

The insulin (INS) gene is the most important of the non-human leukocyte antigen (HLA) genes involved in the pathogenesis of Type 1 Diabetes (T1D), and it may serve as an immunomodulatory agent preventing or halting $\beta$ cell stress and/or cell death $(1,2)$. As the genetic background of T1D has been extensively studied, there is an increasing focus on epigenetics, as it is well established that epigenetic mechanisms contribute to differences in phenotypes via gene hyperexpression or gene silencing (3-5). Epigenetics is an important interpretive link connecting the complex interactions between genetics and environmental factors that lead to the development of T1D. Epigenetic modifications more specifically contribute to the pathogenesis of T1D primarily by regulating the expression of genes that predispose an individual to T1D. Epigenetic changes may serve as biomarkers of early diagnosis of a disease in genetically predisposed individuals, and as potential targets of therapeutic intervention through reversal of their enzymatic activity $(6,7)$.

DNA methylation, an important epigenetic mechanism may serve a vital role in the pathogenesis of T1D. It can suppress gene transcription and occurs at the promoter region of the INS gene, at specific sites, called cytosine-guanosine (CpGs) islands (8). These CpGs islands are frequently observed in close proximity to the transcriptional start site (TSS) (9). DNMT1, DNMT3A and DNMT3B are members of the DNA methyltransferases (DNMTs) gene family which catalyze cytosine methylation. DNMTs are highly expressed during the progression of diabetes as a result of induced methylation (10). Following $\beta$ cell destruction by cytotoxic T lymphocytes, differentially methylated DNA enters the circulation (11).

The few studies that have addressed the issue of INS gene promoter methylation status in T1D patients reported contradictory results (12-18). Thus, it still remains questionable whether 
hypermethylation or hypomethylation of INS gene promoter is a reliable marker of T1D appearance or progression.

The aim of the present study was to investigate the pattern of CpG methylation of the INS gene promoter in children and adolescents of Greek origin with T1D and compare this with a control group.

\section{Patients and methods}

Determination of the sample size. For the calculation of sample size, we used the formula $\left[\mathrm{N}=2 * \sigma^{2} *\left(\mathrm{Z}_{\alpha}+\mathrm{Z}_{1-\beta}\right)^{2} / \delta^{2}\right]$, where $\mathrm{N}$ was the number of patients required in each study group, $Z_{\alpha}$ was a constant equal to 1.960 at a $5 \%$ statistical significance level, $Z_{1-\beta}$ corresponded to a value of 0.842 for achieving a statistical power of $80 \%, \delta$ was the expected detectable difference in the INS gene methylation status between intervention and the control group (that was the primary end point of the study, estimated to be 5\%), while $\sigma$ was its estimated SD in the healthy population (assigned a value of 5\%) (14). Based on these data, the number of patients needed in each study group was calculated to be 16 .

Participants. A total of 20 children and adolescents (12 males and 8 females) with T1D who met the diagnostic criteria of T1D as defined by the International Society for Pediatric and Adolescent Diabetes as well as the American Diabetes Association criteria $(19,20)$ were recruited from the Pediatric Diabetes Outpatient Clinic of the Fourth Department of Pediatrics, at Papageorgiou General Hospital of Thessaloniki between December 2015 and February 2019. Additional inclusion criteria were optimal glycaemic control with glycated hemoglobin $<7.5 \%$, absence of comorbidities (lipid, thyroid or celiac disease) or other autoimmune diseases, and a negative infection history for at least the previous 15 days.

The control group consisted of 20 healthy non-obese young subjects matched for age, sex and body mass index (BMI) without personal or family history of autoimmune diseases, and no history of infection for the last 15 days. These children were evaluated in the General Pediatric Outpatient Clinic of the same hospital for any reason other than T1D, such as health certificates, drug prescription or preventive clinical/laboratory evaluation. Subjects were clinically examined and their weight (seca 711 Scale; Seca, $\mathrm{GmbH}$ ) and height was measured (Harpenden stadiometer; Veeder-Root), and their BMI was calculated as $\mathrm{kg} / \mathrm{m}^{2}$. Medical history, clinical examination and laboratory findings were recorded. The age range of both groups was 2-17 years (median age of T1D group 13.6 years, median age of control group 14 years) and they all had no personal or family history of other autoimmune diseases. Subgrouping of participants into prepubertal and pubertal groups was performed after clinical examination by the same pediatric endocrinologist and application of the Tanner and Marshal criteria for pubertal development (prepubertal group, Tanner stage I; pubertal group, Tanner stages II, III, IV and V) (21,22). Whole blood samples were collected from both groups after a 12 -h fasting period and stored immediately at $-80^{\circ} \mathrm{C}$ until further use.

Parents or guardians of the participants signed the written informed consent form, which was designed according to the
Declaration of Helsinki for research involving humans (23). The Bioethics Committee of the School of Medicine of the Faculty of Health Sciences of the Aristotle University of Thessaloniki approved the present research protocol (approval no. 185/30.12.2015).

The protocol was also declared at Clinical Trials.gov as Methylation of DNA in Children and Adolescents with Type 1 Diabetes Mellitus (METHYLDIAB; ClinicalTrials. gov Identifier, NCT04139369).

DNA extraction, bisulfite treatment and PCR. The studied CpGs in close proximity to the INS promoter were chosen according to similar studies $(12,14)$. All experimental procedures were performed at the Laboratory of Biological Chemistry of School of Medicine of the Faculty of Health Sciences of the Aristotle University of Thessaloniki.

Isolation of genomic DNA was performed from blood samples using the DNA extraction kit QIAamp ${ }^{\circledR}$ DNA Blood Mini kit (Qiagen, Inc.) according to the manufacturer's protocol. Isolated DNA samples were quantified spectrophotometrically using the OD ratio 260/280 (1 OD=50 $\mu \mathrm{g} / \mathrm{ml})$ using a BioPhotometer 6131 (Eppendorf AG). Bisulfite-treatment was performed with $300 \mathrm{ng}$ DNA from each sample using an EZ DNA Methylation-Gold kit (Zymo Research Corp.) according to the manufacturer's protocol. Treatment with sodium bisulfate converts unmethylated cytosine residues into uracil residues, whereas methylated cytosines remain unchanged under the same conditions (24). For amplification of the INS gene promoter, the sequences of the primers were: INS forward, 5'-TATTTTGGAATTTTGAGTTTA TT-3' and INS reverse, 5'-AACAAAAATCTAAAA ACA ACAA-3'. Additional, overhang adapter sequence was added to the gene-specific primers for the regions to be targeted (Nextera Transposase Adaptors; Illumina, Inc.), for prompt construction of the NGS libraries. The sequences of the Transposase Adaptors used were: Read1_INSForward 5'-TCG TCGGCAGCGTCAGATGTGTATAAGAGACAG-3' and Read2_INSReverse 5'-GTCTCGTGGGCTCGGAGATGT GTATAAGAGACAG-3'. PCR products were amplified using a low temperature ramping instrument (9700 Thermal Cycler; Eppendorf AG; cat. no. 5341) using the preset 9600 emulation mode. The reaction solution consisted of AmpliTaq Gold DNA Polymerase with Buffer II and $\mathrm{MgCl}_{2}$ (Applied Biosystems; Thermo Fisher Scientific, Inc.). The total reaction volume was $25 \mu \mathrm{l}$, which consisted of $1.3 \mu \mathrm{l}$ bisulfite-treated DNA, $2.5 \mu \mathrm{l} 10 \mathrm{x}$ Buffer (100 mM Tris- $\mathrm{HCl}, \mathrm{pH} 8.3,500 \mathrm{mM} \mathrm{KCl})$, $0.2 \mu \mathrm{M}$ of each primer, $200 \mu \mathrm{M}$ dNTPs mix, $2 \mathrm{mM} \mathrm{MgCl}_{2}$ and 1.25 units AmpliGold Taq Polymerase. PCR conditions were: Initial denaturation at $95^{\circ} \mathrm{C}$ for $3 \mathrm{~min}$; followed by 40 cycles of $95^{\circ} \mathrm{C}$ denaturation for $30 \mathrm{sec}, 55^{\circ} \mathrm{C}$ annealing for $30 \mathrm{sec}$, and $72^{\circ} \mathrm{C}$ extension for $2.5 \mathrm{~min}$; and subsequently followed by a $1 \mathrm{~min}$ final extension step at $72^{\circ} \mathrm{C}$. After purification of the PCR products using NucleoMag NGS Clean-up and Size Select (Macherey-Nagel, GmbH; cat. no. 744970.5.), they were pooled at similar molar quantities and submitted for library construction according to manufacturer's protocol, (Nextera XT DNA Library Preparation kit; Illumina, Inc.). For NGS reactions, paired-end reads were selected at $2 \times 250$ base pair read length formation, on the Illumina MiSeq platform. 
Analysis of the sequence reads was performed using FASTQ files and methylation status was estimated using ampliMethProfiler (25), a python-based pipeline for targeted deep bisulfite sequenced amplicons. The methylation status was analyzed at $10 \mathrm{CpG}$ sites of the INS gene promoter around the TSS site (human genome 11; INS, NCBI, ref seq NG_007114.1).

Statistical analysis. Data were analyzed using SPSS version 19.0 (IBM, Corp). The methylation percentage in each of the different examined loci constitutes a continuous variable that represents the epigenetic alteration. Thus, every participant in the study was assigned a percentage of methylation for each examined locus. In order to determine any differences in the state of methylation amongst the participants in the study group and the controls, methylation percentage was compared between the two groups, as a continuous variable. Regarding any differences in methylation, the mean methylation status across groups was compared. Continuous variables were expressed as the mean \pm standard deviation (SD) for normally distributed data and as the median (min-max) for non-normally distributed data. A Shapiro-Wilk test was used to examine the normality of distribution. Comparison of variables between the two groups was performed using either a Student's t-test or a Mann-Whitney U-test. Categorical variables among groups were compared using a $\chi^{2}$ test. Correlations between variables was assessed using a Spearman's Rho correlation coefficient. $\mathrm{P}<0.05$ was considered to indicate a statistically significant difference.

\section{Results}

The clinicopathological characteristics of the study population are shown in Table I. The methylation status as well as the differences between the two groups analyzed are presented in Table II. BMI z-scores from both groups was evaluated (Table I). The overall mean methylation percentage in patients with T1D did not differ compared with the healthy controls. Methylation was significantly increased at position -345 in the T1D group of the INS gene $(\mathrm{P}=0.02)$ and a trend towards increased methylation in the T1D group at position $-102(\mathrm{P}=0.06)$.

Correlation analysis of both age distribution of the study population and age at diagnosis of T1D was performed. Age of individuals and age at diagnosis of T1D was not correlated with methylation status in any of the examined positions. Additionally, mean methylation levels in all the studied loci of the insulin promoter was not correlated with the age of participants at examination or diagnosis of the disease. Finally, when the study population were sub-grouped into prepubertal children and adolescents, there was no difference in methylation status observed between the two age subgroups, at any of the studied insulin promoter gene positions, in either the diabetic individuals or controls.

A correlation matrix showed the methylation values (\%) at various INS gene CpG sites amongst patients with T1D (Table III). Fig. 1 shows part of the INS promoter sequence upstream and downstream of the TSS and Fig. 2 shows an agarose gel electrophoresis analysis of PCR products using modified genomic DNA isolated from patients with T1D and controls.
Table I. Characteristics of the experimental and control cohorts.

\begin{tabular}{lcc}
\hline Characteristics & T1D patients & Controls \\
\hline Number & 20 & 20 \\
Sex, female/male & $8 / 12$ & $11 / 9$ \\
Age, years $^{\mathrm{a}}$ & $13.18 \pm 3.79$ & $13.93 \pm 3.80$ \\
Age at onset, years $^{\mathrm{a}}$ & $7.03 \pm 4.00$ & - \\
BMI, kg/m $^{2 \mathrm{a}}$ & $20.34 \pm 2.99$ & $19.12 \pm 1.66$ \\
BMI z-score $^{\mathrm{a}}$ & $0.51 \pm 0.79$ & - \\
Diabetes duration, years $^{\mathrm{a}}$ & $6.15 \pm 4.12$ & - \\
HbA1c, $\%^{\mathrm{a}}$ & $7.76 \pm 0.94$ & - \\
\hline
\end{tabular}

${ }^{\mathrm{a}}$ Mean \pm standard deviation. T1D, Type 1 Diabetes; BMI, body mass index; HbA1c, glycated hemoglobin.

\section{Discussion}

Human studies showed that, most notably, unmethylated DNA of the INS gene is a valuable marker of silent $\beta$ cell stress and death, while that was not the case with other biomarkers such as proinsulin/C-peptide ratio and various non-coding RNAs $(12-14,16-18,26)$. The observed increase of unmethylated INS gene in patients that developed T1D was correlated with a decrease in insulin secretion, indicative of active $\beta$ cell loss. Unmethylated INS DNA may thus be considered a novel biomarker of ongoing $\beta$ cell death used for the evaluation and prediction of progression of T1D progression (18).

In the present study, ten $\mathrm{CpG}$ sites in a close proximity with the TSS of INS gene were analyzed in order to evaluate the methylation status in patients with T1D of Greek origin, with a mean diabetes duration of $\sim 6$ years. Despite the fact that the $\mathrm{CpG}$ position sites were mostly the same compared with other studies $(12,14,15,17)$, in the present study, position -345 was found to exhibit increased methylation compared with the controls. Furthermore, position -102 showed a tendency for methylation.

Hypermethylation of the INS gene promoter $\mathrm{CpG}$ at position -345 observed in the present study is in partial agreement with the tissue-specific pattern of methylation proposed by Kuroda et al (17). They found that in insulin-expressing $\beta$ cells, this site was completely demethylated, whereas in non-insulin expressing human pancreatic exocrine tissue, it was methylated. In the present study, promoter methylation of the INS gene was evaluated in genomic DNA extracted from whole blood cells.

Regarding INS gene promoter CpG methylation at position -102 , the tendency for increased methylation was in contrast to the results of previous studies $(12,14)$, which reported either hypomethylation or comparable methylation levels. It is worth mentioning that the methodology of the study of Fradin et al (14) that failed to detect any difference in methylation is comparable to the one used in the present study, as DNA was extracted from non-immortalised human whole blood cells, using pyrosequencing, 7.5 years after T1D diagnosis. Nevertheless, based on the inconsistency of the results, this trend may be an incidental finding and requires further verification. 
Table II. Methylation of the $\mathrm{CpG}$ sites in the INS gene promoter.

\begin{tabular}{|c|c|c|c|}
\hline \multirow[b]{2}{*}{ CpG site ${ }^{b}$} & \multicolumn{3}{|c|}{ Methylation, $\%^{\mathrm{a}}$} \\
\hline & $\mathrm{T} 1 \mathrm{D}, \mathrm{n}=20$ & Control group, $n=20$ & P-value \\
\hline Mean methylation (range) & $84.13 \pm 3.6(77-92)$ & $82.28 \pm 2.8(76-87)$ & 0.084 \\
\hline $1 /-357$ & $94.00 \pm 5.0$ & $90.78 \pm 7.9$ & 0.15 \\
\hline $2 /-345$ & $96.32 \pm 2.2$ & $93.28 \pm 4.5$ & 0.02 \\
\hline $3 /-234$ & $91.02 \pm 6.3$ & $89.58 \pm 8.4$ & 0.65 \\
\hline $4 /-206$ & $63.16 \pm 8.9$ & $62.30 \pm 9.8$ & 0.86 \\
\hline $5 /-180$ & $85.78 \pm 6.6$ & $84.35 \pm 9.9$ & 0.82 \\
\hline $6 /-135$ & $56.65 \pm 9.8$ & $52.82 \pm 1.0$ & 0.25 \\
\hline $7 /-102$ & $90.01 \pm 3.6$ & $86,53 \pm 6,0$ & 0.06 \\
\hline $8 /-69$ & $80.28 \pm 6.2$ & $77.72 \pm 8.4$ & 0.32 \\
\hline $9 /-19$ & $91.51 \pm 5.2$ & $89.05 \pm 9.2$ & 0.67 \\
\hline $10 /+60$ & $96.37 \pm 2.7$ & $97.91 \pm 1.3$ & 0.1 \\
\hline
\end{tabular}

${ }^{\mathrm{a}}$ Mean \pm standard deviation. ${ }^{\mathrm{b}} \mathrm{CpG}$ sites are indicated by the first number and the second numbering indicates the actual sites of the INS gene promoter region proximal to TSS. T1D, Type 1 Diabetes; CpG site, Cytosine-Guanine site; INS, insulin gene.

Table III. Correlation matrix of the methylation values at various CpG sites of the INS gene promoter among T1D patients.

\begin{tabular}{|c|c|c|c|c|c|c|c|c|c|c|}
\hline CpG site & -357 & -345 & -234 & -206 & -180 & -135 & -102 & -69 & -19 & 60 \\
\hline \multirow[t]{2}{*}{ INS-357 } & & 0.241 & $0.453^{\mathrm{a}}$ & 0.081 & 0.356 & $0.480^{\mathrm{a}}$ & 0.420 & 0.191 & 0.430 & -0.020 \\
\hline & & 0.307 & 0.045 & 0.734 & 0.123 & 0.032 & 0.066 & 0.420 & 0.058 & 0.935 \\
\hline \multirow[t]{2}{*}{ INS-345 } & & & 0.346 & 0.083 & 0.030 & 0.011 & -0.186 & 0.298 & 0.195 & 0.090 \\
\hline & & & 0.135 & 0.729 & 0.900 & 0.965 & 0.431 & 0.202 & 0.409 & 0.705 \\
\hline \multirow[t]{2}{*}{ INS-234 } & & & & $0.451^{\mathrm{a}}$ & $0.487^{\mathrm{a}}$ & 0.215 & 0.105 & 0.259 & -0.092 & 0.105 \\
\hline & & & & 0.046 & 0.029 & 0.363 & 0.659 & 0.271 & 0.701 & 0.659 \\
\hline \multirow[t]{2}{*}{ INS-206 } & & & & & 0.400 & 0.223 & 0.314 & 0.271 & -0.117 & 0.223 \\
\hline & & & & & 0.081 & 0.346 & 0.177 & 0.248 & 0.622 & 0.346 \\
\hline \multirow[t]{2}{*}{ INS-180 } & & & & & & 0.328 & 0.153 & 0.021 & -0.012 & 0.408 \\
\hline & & & & & & 0.158 & 0.519 & 0.930 & 0.960 & 0.075 \\
\hline \multirow[t]{2}{*}{ INS-135 } & & & & & & & 0.395 & 0.138 & 0.323 & 0.069 \\
\hline & & & & & & & 0.084 & 0.561 & 0.164 & 0.772 \\
\hline \multirow[t]{2}{*}{ INS-102 } & & & & & & & & 0.095 & 0.141 & 0.029 \\
\hline & & & & & & & & 0.691 & 0.552 & 0.905 \\
\hline \multirow[t]{2}{*}{ INS-69 } & & & & & & & & & 0.068 & 0.245 \\
\hline & & & & & & & & & 0.777 & 0.298 \\
\hline \multirow[t]{2}{*}{ INS-19 } & & & & & & & & & & -0.176 \\
\hline & & & & & & & & & & 0.458 \\
\hline
\end{tabular}

Spearman's Rho R-value (upper), Spearman's Rho P-value (lower). ${ }^{\mathrm{a}} \mathrm{P}<0.05$. CpG site, Cytosine-Guanine site; T1D, Type 1 Diabetes; INS, insulin gene.

Regarding the remaining INS gene promoter $\mathrm{CpG}$ sites; $-357,-234,-206,-180,-135,-69$ and -19 , there were no statistically significant differences in the methylation levels between patients and healthy subjects observed in the present study. This is in agreement with the findings of Fradin et al (14) only for CpG sites at -69 and -206. A study quantitating the hyper- or hypomethylation at the $\mathrm{CpG}$ position -69 in pediatric patients with new-onset T1D, by droplet digital PCR, found elevated levels of unmethylated and methylated DNA sequences of the INS gene compared with the control group, and this elevation may arise from $\beta$ cells and other cell types related with T1D autoimmunity. The levels of methylated DNA remained high and the levels of unmethylated DNA dropped after eight weeks of onset of the disease, and they both returned to control levels 1 -year post-onset (15). In the present study, comparable methylation patterns were observed at $\mathrm{CpG}$ position -69 between 


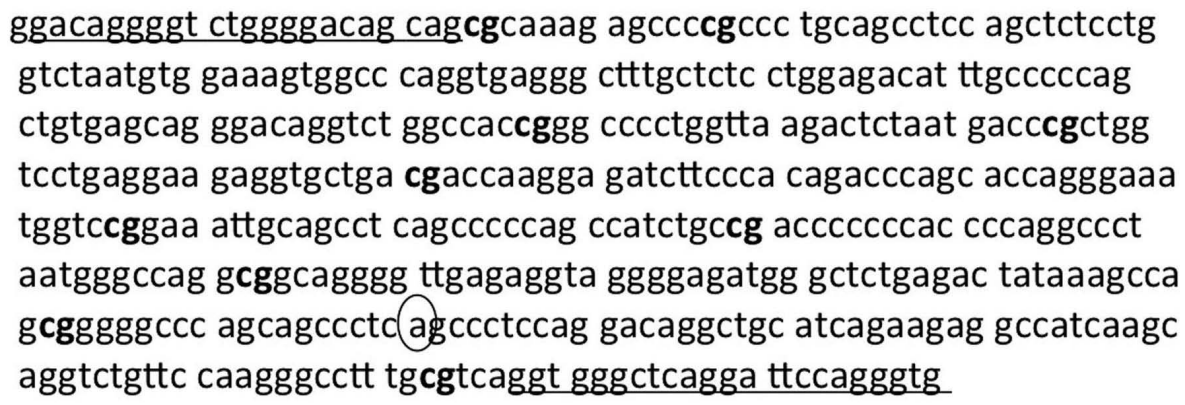

Figure 1.INS gene promoter region sequence upstream and downstream of the TSS according to the NCBI (human genome 11; INS, NCBI, ref seq NG_007114.1). The $10 \mathrm{CpG}$ sites analyzed are shown in bold. The CpG sites are numbered according to their distance from the TSS. The TSS site is numbered as +1 . The underlined sequences represent the positions of the primers used for PCR. TSS, transcription start site; INS, insulin.

A

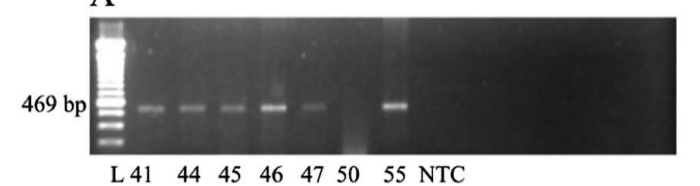

$\mathrm{C}$

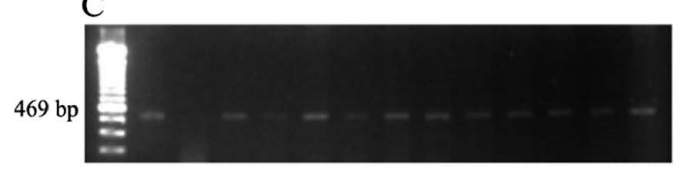

$\begin{array}{llllllllllll}\mathrm{L} & 4 & 7 & 12 & 13 & 15 & 20 & 21 & 22 & 24 & 25 & 36\end{array}$
B

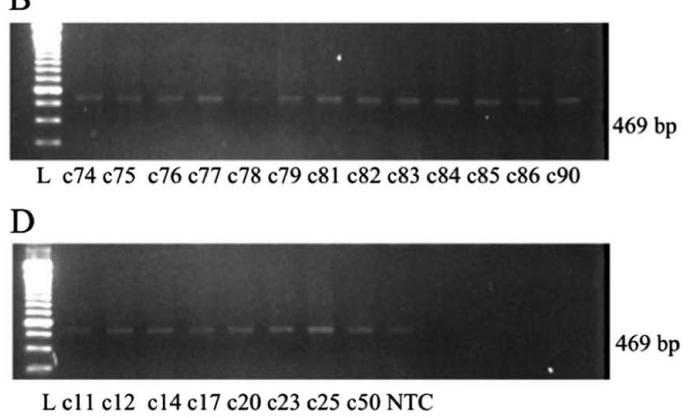

Figure 2. Agarose gel electrophoresis (A-D) of the PCR products from modified genomic DNA isolated from patients with Type 1 Diabetes and the controls. Numbers under each gel represent the patient ID for the present study. L, 100 bp molecular weight marker, NTC, non-template control; c, control.

patients and controls. However, it cannot be ruled out that at onset, there may have been a difference in the methylation levels at this $\mathrm{CpG}$ site, or indeed, any other $\mathrm{CpG}$ site. Thus, additional studies are required, examining the levels of methylation at the $\mathrm{CpG}$ sites in the INS promoter gene at the onset of the disease, and assessing the changes in the methylation levels over time.

In animal studies, analysis of the mouse Ins 1 and Ins 2 promoters revealed unique demethylation of INS gene in $\beta$ cells suggesting it to be a strong biomarker of $\beta$ cell death (12,17,27-30). DNA methylation was found to regulate insulin gene expression in the Ins1 and Ins 2 genes in non-obese diabetic (NOD) mice, whereas increases in cytokine transcription as NOD mice age can induce methylation of markers by activating methyltransferases (10).

In the present study, NGS instead of Sanger sequencing was used, as NGS has the ability to sequence, in parallel, thousands to millions of DNA fragments, with the ability to detect mutations or variants in the DNA sequence (31-34). In addition, NGS has high sensitivity and specificity, even when sequencing small genomes, and provides specific information of the methylation status of each $\mathrm{CpG}$. To the best of our knowledge, only one study in the literature reported the use of a similar DNA sequencing method in circulating free DNA in newly diagnosed T1D patients (16).

According to the results of the present study, methylated DNA leading to INS gene silencing remains elevated at positions -345 and -102 long after the onset of diabetes. However, there was no evidence of SNPs at the positions -345 and -102 in T1D samples (data not shown). A previous study performed at the onset of T1D detected unmethylated INS DNA (16). To the best of our knowledge, the present study is the first to address the methylation status of the INS gene a long time after the initial diagnosis with NGS, thus highlighting potential future research opportunities to investigate the effect of hyperglycemia on alteration of $\mathrm{CpG}$ methylation status. As methylation can vary over time and metabolic and immunological factors may serve a role in the alteration of methylation dependent on the duration of diabetes, glycemic control, BMI and low-grade inflammation, further studies are required to clarify if the epigenetic changes identified are associated with T1D or are incidental findings.

In the present study, children and adolescents with T1D exhibited good glycemic control, a normal BMI, and no signs and symptoms of low-grade inflammation, thus reducing the potential impact of these factors on the level of methylation over time.

As it is difficult to measure the methylation status directly in the pancreatic islets, whole blood DNA was used as an acceptable alternative to detect the methylation status, serving as a liquid biopsy. Furthermore, these data indicate that methylated compared with unmethylated DNA at certain CpG sites may possibly serve as an even more specific and reliable methylation pattern, and it is may be worth investigating the influence of long term glycemic control of T1D.

The present study has some limitations: The participants were only of Greek origin and their number was limited. Larger scale studies are required to confirm the findings pf the present study. In the future, patients recently diagnosed with T1D diabetes will also be assessed. 
There are no concrete explanations which account for the discrepancies between our results and those of previous studies. They may possibly be attributed to the different time frames after disease onset to examination, the ethnicity of the groups assessed, differences in the PCR methods used or the different times of blood sample collection compared with the other studies mentioned above.

In conclusion, according to our data the methylation level in the promoter region of the INS gene quantitated using NGS, remains elevated in certain $\mathrm{CpG}$ sites long after the onset of diabetes. However, the DNA methylation status in other $\mathrm{CpG}$ sites did not differ between patients with T1D and healthy subjects. Previous studies performed at the onset of T1D detected unmethylated INS DNA. The present study is the first study to assess the hypermethylation status of the INS gene long after the initial diagnosis using NGS, to the best of our knowledge.

\section{Acknowledgements}

Parts of the study have been presented at the 57 and 58th ESPE Annual Meeting (2018 and 2019) and at the 56th PanHellenic Paediatric Congress (2018).

\section{Funding}

This study was funded by the Hellenic Association for the Study and Education of Diabetes Mellitus (grant no. 2015).

\section{Availability of data and materials}

The datasets used and/or analyzed during the present study are available from the corresponding author on reasonable request.

\section{Authors' contributions}

KM and AGT conceived the study. AGT, KM and GT designed the study. KM, AK, AF, IK, AS, VRT and SG collected the data. EPK, KM, AGT and GT analyzed and interpreted the data. KM, AK, VRT AS, SG, AGT, GT, IK, EPK, assisted in writing or revising the manuscript for important intellectual content. All authors read and approved the final manuscript.

\section{Ethics approval and consent to participate}

Parents or guardians provided written informed consent for the inclusion of their children in the present in accordance with the guidelines stated in the Declaration of Helsinki for research involving human subjects. The study protocol was approved by the Bioethics Committee of the Medical Department, Faculty of Health Sciences, Aristotle University of Thessaloniki (approval no. 185/30.12.2015) (Thessaloniki, Greece).

\section{Patient consent for publication}

Not applicable.

\section{Competing interests}

The authors declare that they have no competing interests.

\section{References}

1. Pugliese A: The insulin gene in type 1 diabetes. IUBMB Life 57 463-468, 2005.

2. Steck AK and Rewers MJ: Genetics of type 1 diabetes. Clin Chem 57: 176-185, 2011.

3. Bansal A and Pinney SE: DNA methylation and its role in the pathogenesis of diabetes. Pediatr Diabetes 18: 167-177, 2017.

4. Handy DE, Castro R and Loscalzo J: Epigenetic modifications: Basic mechanism and role in cardiovascular disease. Circulation 17: 2145-2156, 2011.

5. Cano-Rodriguez D and Rots MG: Epigenetic editing: On the verge of reprogramming gene expression at will. Curr Genet Med Rep 1: 170-179, 2016.

6. Dang MN, Buzzetti R and Pozzilli P: Epigenetics in autoimmune diseases with focus on type 1 diabetes. Diabetes Metab Res Rev 29: 8-18, 2013.

7. Wang Z, Xie Z, Lu Q, Chang C and Zhou Z: Beyond genetics: What causes type 1 diabetes. Clin Rev Allergy Immunol 52: 273-286, 2017.

8. Moore LD, Le T and Fan G: DNA methylation and its basic function. Neuropsychopharmacology 38: 23-38, 2013.

9. Deaton AM and Bird A: $\mathrm{CpG}$ islands and the regulation of transcription. Genes Dev 15: 1010-1022, 2011.

10. Riu J, Deng S, Lebastchi J, Clark PL, Usmani-Brawn S and Herold KC: Methylation of insulin DNA in response to proinflammatory cytokines during the progression of autoimmune diabetes in NOD mice. Diabetologia 59: 1021-1029, 2016.

11. Zhang K, Lin G, Han Y, Xie J and Li J: Circulating unmethylated insulin DNA as a potential non-invasive biomarker of beta cell death in type 1 diabetes: A review and future prospect. Clin Epigenetics 26: 44, 2017.

12. Husseiny MI, Kaye A, Zebabua E, Kandeel F and Ferreri K: Tissue-specific methylation of human insulin gene and PCR assay for monitoring beta cell death. PLoS One 9: e94591, 2014.

13. Neiman D, Moss J, Hecht M, Magenheim J, Piyanzin S, Shapiro AM, de Koning EJ, Razin A, Cedar H, Shemer R and Dor Y: Islet cells share promoter hypomethylation independently of expression, but exhibit cell-type-specific methylation in enhancers. Proc Natl Acad Sci USA 19: 13525-13230, 2017.

14. Fradin D, Le Fur S, Mille C, Naoui N, Groves C, Zelenika D, McCarthy MI, Lathrop M and Bougnères P: Association of the CpG methylation pattern of the proximal insulin gene promoter with type 1 diabetes. PLoS One 7: 336278, 2012.

15. Fisher MM, Watkins RA, Blum J, Evans-Molina C, Chalasani N, DiMeglio LA, Mather KJ, Tersey SA and Mirmira RG: Elevations in circulating methylated and unmethylated preproinsulin DNA in new-onset type 1 diabetes. Diabetes 64: 3867-3872, 2015.

16. Lehmann-Werman R, Neiman D, Zemmour H, Moss J, Magenheim J, Vaknin-Dembinsky A, Rubertsson S, Nellgård B, Blennow K, Zetterberg $\mathrm{H}$, et al: Identification of tissue-specific cell death using methylation patterns of circulating DNA. Proc Natl Acad Sci USA 113: E1826-E1834, 2016.

17. Kuroda A, Rauch TA, Todorov I, Ku HT, Al-Abdullah I, Kandeel F, Mullen Y, Pfeifer GP and Ferreri K: Insulin gene expression is regulated by DNA methylation. PLoS One 9: e6953, 2009.

18. Herold KC, Usmani-Brown S, Ghazi T, Lebastchi J, Beam CA, Bellin MD, Ledizet M, Sosenko JM, Krischer JP and Palmer JP; Type 1 Diabetes TrialNet Study Group: $\beta$ cell death and dysfunction during type 1 diabetes development in at-risk individuals. J Clin Invest 125: 1163-1173, 2015.

19. Mayer-Davis EJ, Kahkoska AR, Jefferies C, Dabelea D, Balde N, Gong CX, Aschner P and Craig ME: ISPAD Clinical practice consensus guidelines 2018: Definition, epidemiology, and classification of diabetes in children and adolescents. Pediatr Diabetes 19: 7-19, 2018.

20. American Diabetes Association: Classification and diagnosis of diabetes: Standards of medical care in diabetes-2018. Diabetes Care 41 (Suppl 1): S13-S27, 2018.

21. Marshall WA and Tanner JM: Variations in the pattern of pubertal changes in boys. Arch Dis Child 45: 13-23, 1970.

22. Marshall WA and Tanner JM: Variations in pattern of pubertal changes in girls. Arch Dis Child 44: 291-303, 1969.

23. World Medical Association: World medical association declaration of Helsinki: Ethical principles for medical research involving human subjects. JAMA 310: 2191-2194, 2013.

24. Li Y and Tollefsbol TO: DNA methylation detection: Bisulfite genomic sequencing analysis. Methods Mol Biol 791: 11-21, 2011. 
25. Scala G, Affinito O, Palumbo D, Florio E, Monticelli A, Miele G, Chiariotti L and Cocozza S: AmpliMethProfiler: A pipeline for the analysis of $\mathrm{CpG}$ methylation profiles of targeted deep bisulfite sequenced amplicons. BMC Bioinformatics 25: 484, 2016.

26. Mirmira RG, SimsEK, Syed F and Evans-Morina C: Biomarkers of $\beta$-cell stress and death in type 1 diabetes. Curr Diab Rep 16 95, 2016.

27. Husseiny MI, Kuroda A, Kaye AN, Nair I, Kandeel F and Ferreri K: Development of a quantitative methylation-specific polymerase chain reaction method for monitoring beta cell death in type 1 diabetes. PLoS One 7: e47942, 2012.

28. Fisher MM, Chumbiauca CN, Mather KJ, Mirmira RG and Tersey SA: Detection of islet $\beta$-cell death in vivo by multiplex PCR analysis of differentially methylated DNA. Endocrinology 154: 3476-3481, 2013

29. Usmani-Brown S, Lebastchi J, Steck AK, Beam S, Herold KC and Ledizet M: Analysis of $\beta$-cell death in type 1 diabetes by droplet digital PCR. Endocrinol 155: 3694-3698, 2014.
30. Akirav EM, Lebastchi J, Galvan EM, Henegariu O, Akirav M, Ablamunits V, Lizardi PM and Herold KC: Detection of $\beta$ cell death in diabetes using differentially methylated circulating DNA. Proc Natl Acad Sci USA 108: 19018-19023, 2011.

31. Grada A and Weinbrecht K: Next generation sequencing: Methodology and application. J Invest Dermatol 133: e11, 2013.

32. Behjati S and Tarpey PS: What is next generation sequencing? Arch Dis Child Educ Pract Ed 98: 236-238, 2013.

33. Liu L, Li Y, Li S, Hu N, He Y, Pong R, Lin D, Lu L and Law M: Comparison of next generation sequencing systems. J Biomed Biotechnol 2012: 251364, 2012.

34. Buermans HPJ and den Dunnen JT: Next generation sequencing technology: Advantages and applications. Biochim Biophys Acta 1842: 1932-1941, 2014. 